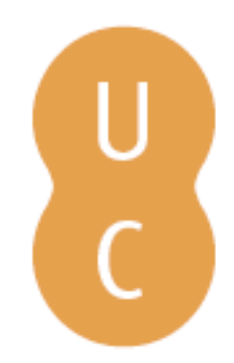

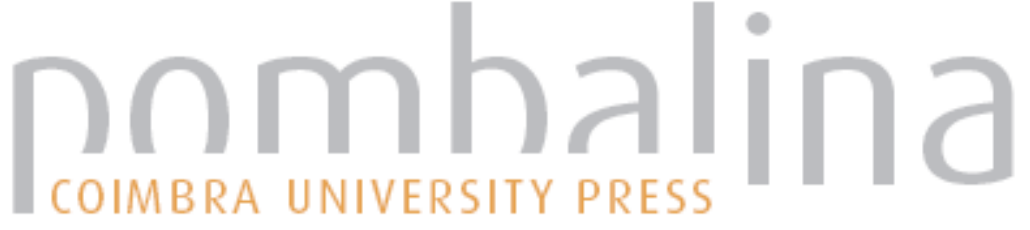

\section{O Museu da Ciência: uma colecção científica do Século das Luzes}

Autor(es): $\quad$ Simões, Carlota; Casaleiro, Pedro; Mota, Paulo Gama

Publicado por: Imprensa da Universidade de Coimbra

URL

persistente:

URI:http://hdl.handle.net/10316.2/38515

DOI:

DOI:http://dx.doi.org/10.14195/978-989-26-0610-1_4

Accessed : $\quad$ 26-Apr-2023 02:40:18

A navegação consulta e descarregamento dos títulos inseridos nas Bibliotecas Digitais UC Digitalis, UC Pombalina e UC Impactum, pressupõem a aceitação plena e sem reservas dos Termos e Condições de Uso destas Bibliotecas Digitais, disponíveis em https://digitalis.uc.pt/pt-pt/termos.

Conforme exposto nos referidos Termos e Condições de Uso, o descarregamento de títulos de acesso restrito requer uma licença válida de autorização devendo o utilizador aceder ao(s) documento(s) a partir de um endereço de IP da instituição detentora da supramencionada licença.

Ao utilizador é apenas permitido o descarregamento para uso pessoal, pelo que o emprego do(s) título(s) descarregado(s) para outro fim, designadamente comercial, carece de autorização do respetivo autor ou editor da obra.

Na medida em que todas as obras da UC Digitalis se encontram protegidas pelo Código do Direito de Autor e Direitos Conexos e demais legislação aplicável, toda a cópia, parcial ou total, deste documento, nos casos em que é legalmente admitida, deverá conter ou fazer-se acompanhar por este aviso. 

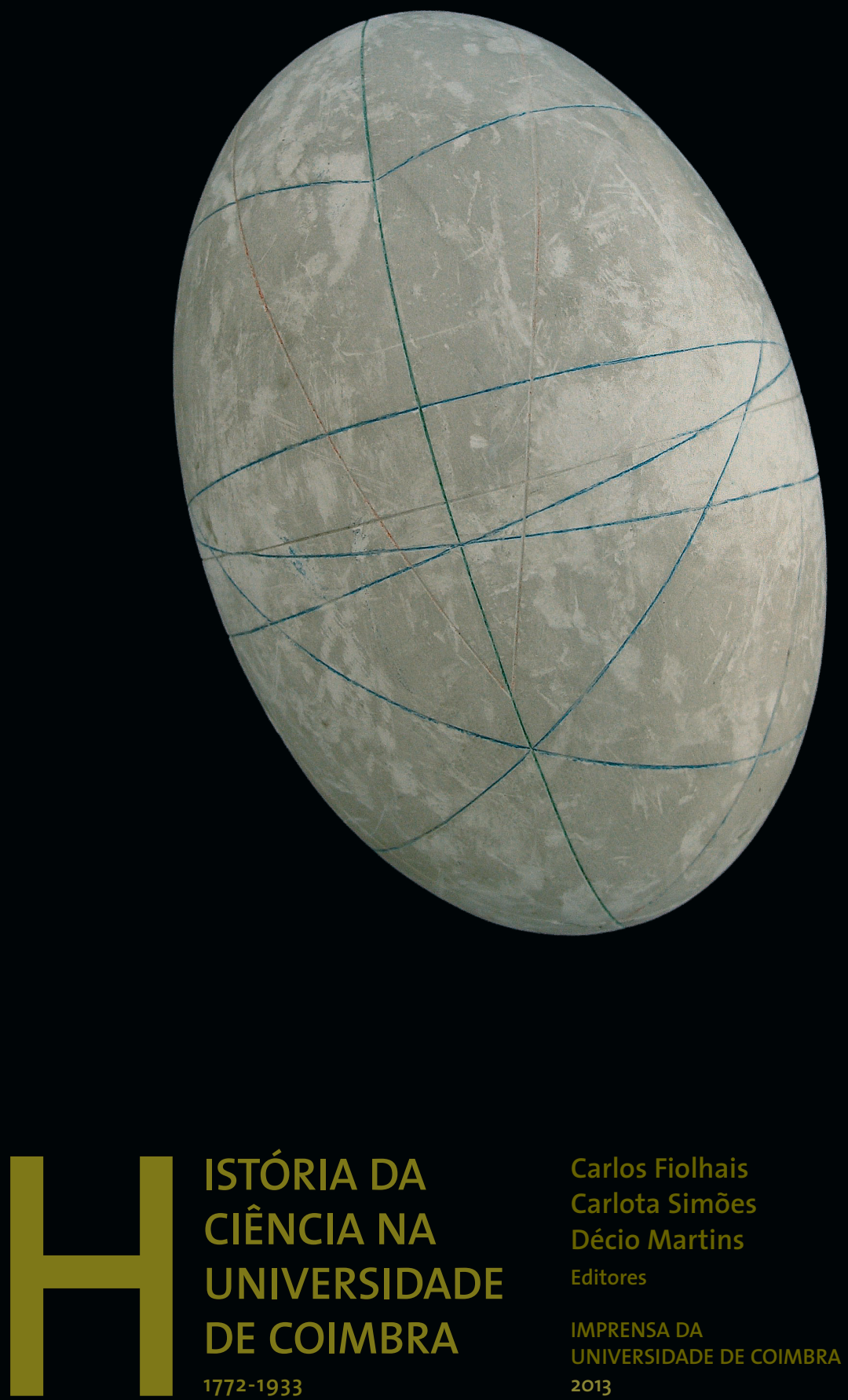

ISTÓRIA DA

CIÊNCIA NA

UNIVERSIDADE

DE COIMBRA

1772-1933
Carlos Fiolhais

Carlota Simões

Décio Martins

Editores

IMPRENSA DA

UNIVERSIDADE DE COIMBRA

2013 
${ }^{1}$ CFC, Departamento de Matemática, Museu da Ciência, Universidade de Coimbra.

${ }^{2}$ Museu da Ciência, Universidade de Coimbra.

${ }^{3}$ Museu da Ciência, Departamento de Antropologia, Universidade de Coimbra.

O Museu da Ciência: Uma Colecção Científica do Século das Luzes ${ }^{1}$

Carlota Simões ${ }^{1}$, Pedro Casaleiro ${ }^{2}$ e Paulo Gama Mota ${ }^{3}$

\section{INTRODUÇÃO}

O Museu da Ciência da Universidade de Coimbra foi inaugurado em Dezembro de 2006. A sua sede está instalada num edifício neoclássico magnificamente recuperado, o Laboratório Chimico, contemporâneo do nascimento da química moderna, construído entre 1773 e 1777 a mando do Marquês de Pombal e o mais antigo edifício laboratório químico do mundo a resistir até aos nossos dias. Os primeiros objectos das colecçôes do Museu da Ciência datam igualmente do Século das Luzes. Muito contribuíram para a riqueza do espólio as Viagens Philosophicas de Alexandre Rodrigues Ferreira, mas também a transferência para Coimbra da colecção de física experimental do Colégio dos Nobres em Lisboa. Parte do acervo do Museu da Ciência pode ser ainda hoje visitada nas salas originais do Século XVIII, no Colégio de Jesus, mais um edifício do complexo jesuítico transformado pelo Marquês de Pombal com o objectivo de promover em Coimbra o ensino experimental das ciências.

\section{O Laboratório Chimico e o Colégio de Jesus}

O Museu da Ciência da Universidade de Coimbra distribui-se por dois edifícios: o Laboratório Chimico, recuperado já durante o séc. XXI, e o Colégio de Jesus, que alberga grande parte das colecções científicas da Universidade de Coimbra. Os dois edifícios foram desenhados pela Casa do Risco, sob orientação do engenheiro militar e tenente-coronel William Elsden, que se salientou como director das Obras da Reforma da Universidade de Coimbra levada a cabo pelo Marquês de Pombal.

\footnotetext{
${ }^{1}$ Comunicação apresentada no VIII Congresso Internacional de Cidades e Entidades do Iluminismo, organização da Câmara Municipal de Vila Real de Santo António e da Associação Internacional de Cidades e Entidades do Fórum do Iluminismo (AiCEi), 6, 7 e 8 de Outubro de 2001, Vila Real de Santo António.
} 


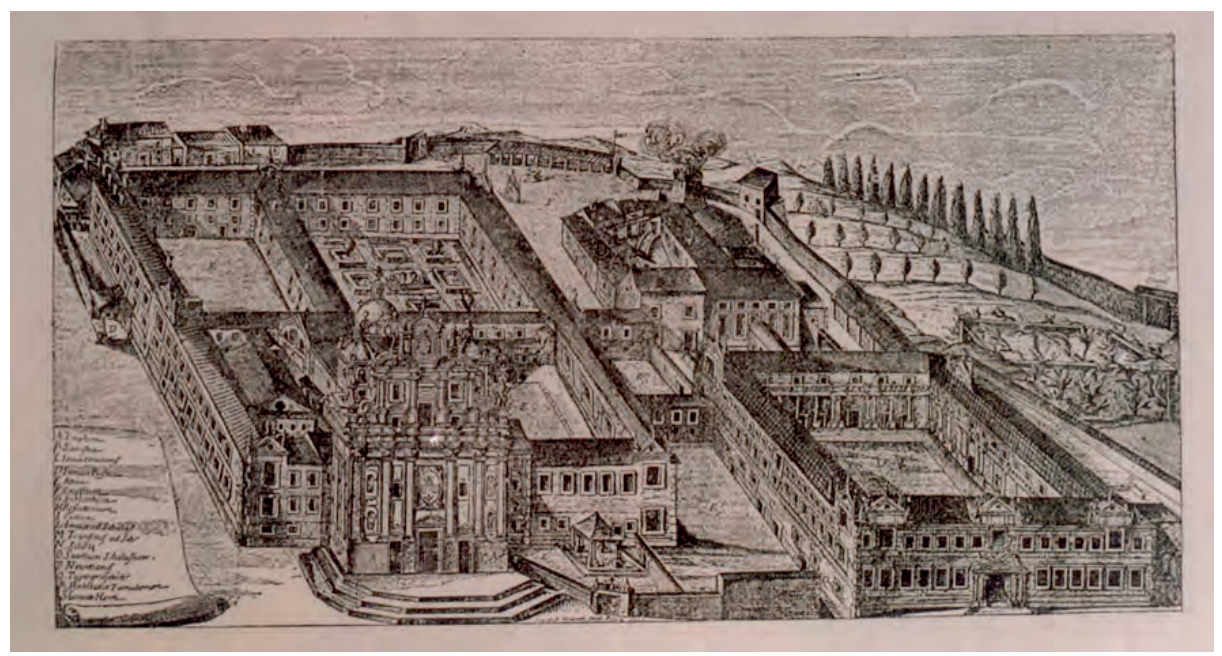

Figura 1 - O complexo jesuítico no séc. XVIII, antes da intervenção Pombalina. À esquerda o Colégio de Jesus, à direita o Colégio das Artes. O Refeitório é o edifício em segundo plano, à direita, e tem ligação directa aos dois colégios (gravura do Séc. XVIII, Museu Nacional Machado de Castro).

Elsden foi fundamental na criação e remodelação dos edifícios da Universidade iluminista, mas foi com o Bispo D. Francisco de Lemos (1735-1822), nomeado Reitor da Universidade de Coimbra em 1770 e Reformador da mesma Universidade em 1772, que a nova mentalidade iluminista se instalou. Os novos Estatutos da Universidade [1] foram publicados logo em 1772 e nenhum lente em exercício antes dessa data viu reconduzidas as suas funçōes. Para leccionar na nova universidade, Pombal trouxe para Coimbra Domenico Vandelli (1730-1816), Doutor em Medicina pela Universidade de Pádua, nomeado Lente de História Natural e Química em 1772; o Padre Monteiro da Rocha (1734-1819), nomeado Lente de Matemática em 1772 e de Astronomia em 1773; Giovanni Antonio Dalla Bella (1730-c.1823), da Universidade de Pádua, nomeado Lente de Física Experimental em 1772; Michele Antonio Ciera, engenheiro de Piemonte, nomeado Lente de Astronomia em 1772.

O Laboratório Chimico foi construído para o ensino da Química, entre 1773 e 1777, materializando a ideologia iluminista do ensino experimental da ciência. Domenico Vandelli foi o seu primeiro Director. Tomé Rodrigues Sobral (1759-1829), que sucedeu a Vandelli, alargou as potencialidades do Laboratório quando o adaptou temporariamente ao fabrico de pólvora para as tropas defensoras da cidade, na sequência da ocupação e saque de Coimbra pelas tropas napoleónicas em 1 de Outubro de 1810, ficando conhecido como o "mestre da pólvora".

No decurso das obras de adaptação do Laboratorio Chimico a Museu, os trabalhos arqueológicos revelaram que o edifício do séc. XVIII fora construído aproveitando a sala do refeitório que servia o complexo dos colégios Jesuítas do séc. XVI, composto pelo Colégio de Jesus e pelo Colégio das Artes (Fig. 1).

A intervenção trouxe à luz, intactas, algumas provas da utilização do edifício pelos jesuítas: várias janelas e um púlpito, bem como as fundações das cozinhas. Os elementos encontrados foram integrados na recuperação do edifício: o púlpito, uma janela 
conservada com a cantaria original, duas janelas no fundo da sala e o vigamento do tecto, do qual se manteve o desenho e os tirantes originais (Fig. 2).

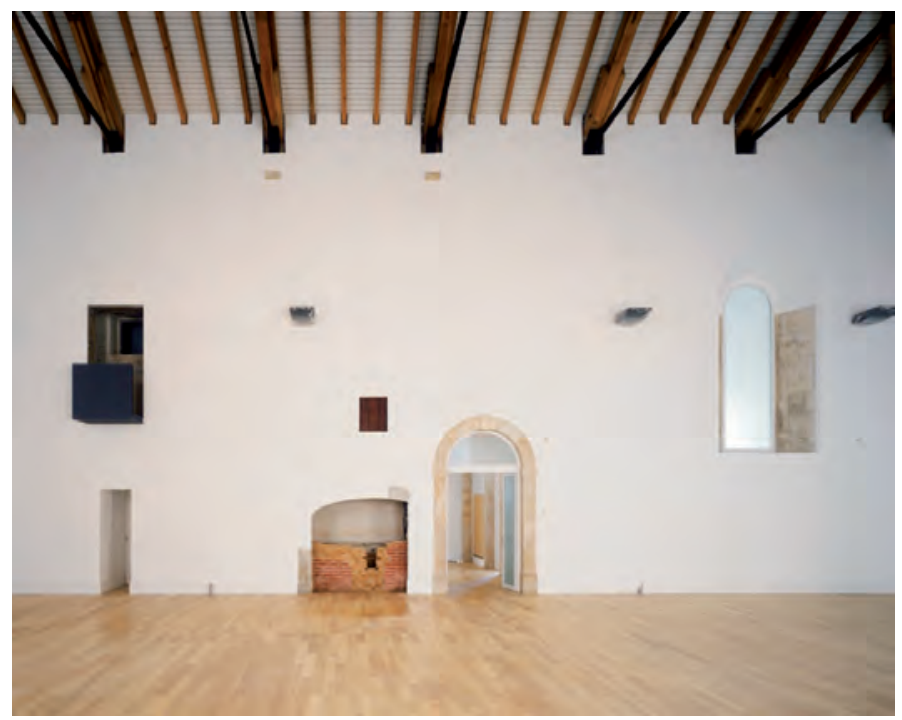

Figura 2 - Parede interior do Laboratorio Chimico onde se identifica o púlpito e uma janela do refeitório jesuíta (fotografia de Emanuel Brás).

O projecto de arquitectura, da responsabilidade dos arquitectos João Mendes Ribeiro, Carlos Antunes e Desirée Pedro, viu reconhecida a sua qualidade com a atribuição dos Prémios de Arquitectura Diogo de Castilho em 2007 e ENOR em 2009 (Fig. 3). O Museu da Ciência foi o vencedor do Prémio Micheletti 2008, que distingue o melhor e mais inovador museu europeu do ano em ciência, técnica e indústria.

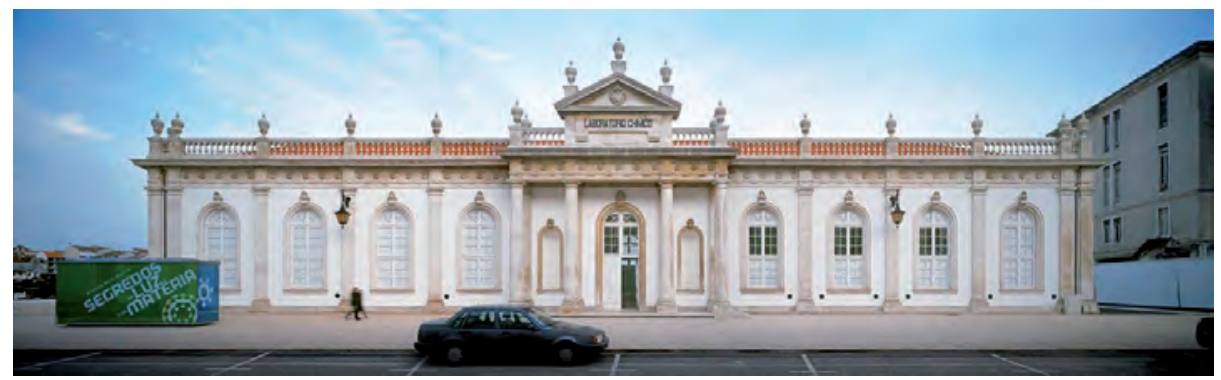

Figura 3 - O Laboratorio Chimico, depois da intervenção do Séc. XXI (fotografia de Emanuel Brás).

O Colégio de Jesus (Fig. 4), face a face com o Laboratório Chimico, alberga hoje as colecções de física, zoologia, geologia, mineralogia e paleontologia. O edifício que chegou aos nossos dias é a reconstrução do antigo Colégio de Jesus, estabelecido em 1542 pela Companhia de Jesus. A intervenção pombalina entre 1773 e 1775 adaptou o colégio de modo a tornar-se um edifício universitário, que passou a albergar os equipamentos destinados ao ensino experimental das ciências. 
Com este espírito foram criados no edifício o Gabinete de História Natural (Fig. 5) e o Gabinete de Física Experimental (Fig. 6), no quadro da Faculdade de Filosofia então criada, preservados no Colégio de Jesus até aos nossos dias, e ainda o Hospital e o Dispensatório Farmacêutico, no quadro da Faculdade de Medicina.

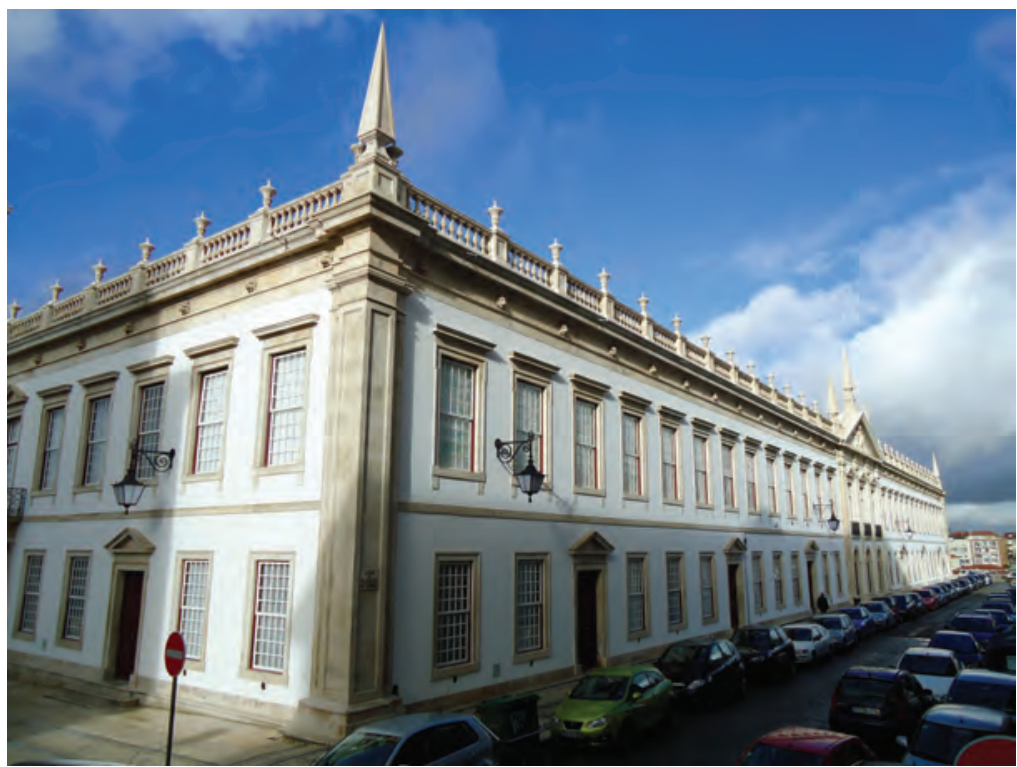

Figura 4 - O Colégio de Jesus (fotografia de Gilberto Pereira).

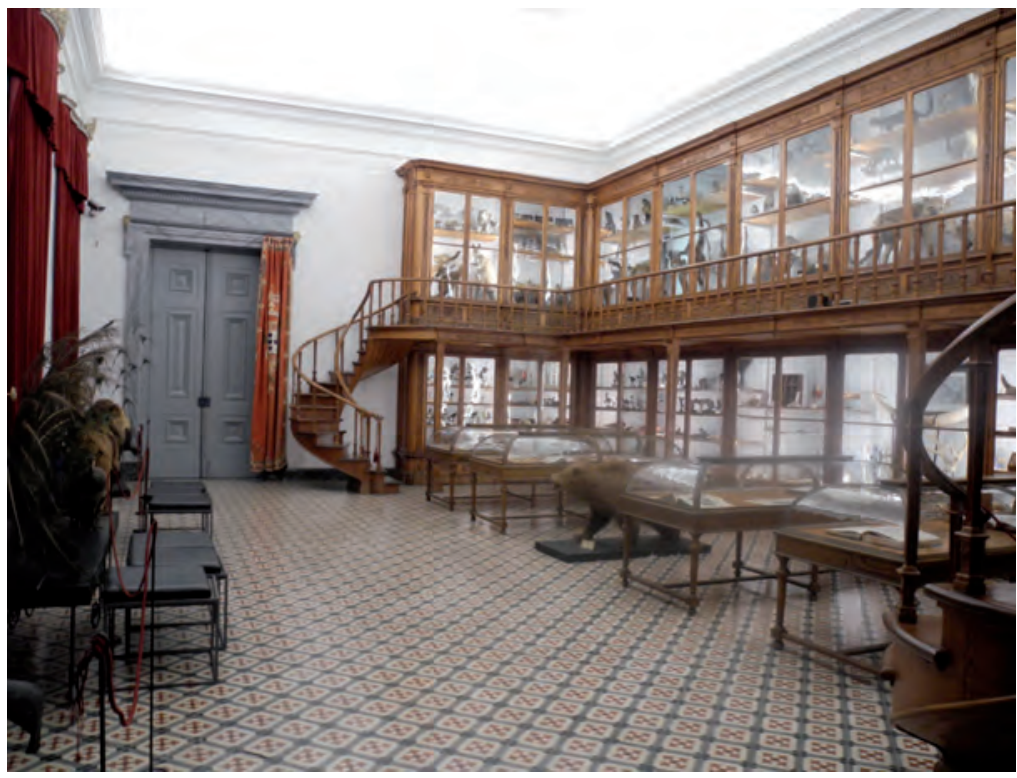

Figura 5 - O Gabinete de História Natural (fotografia de Gilberto Pereira). 


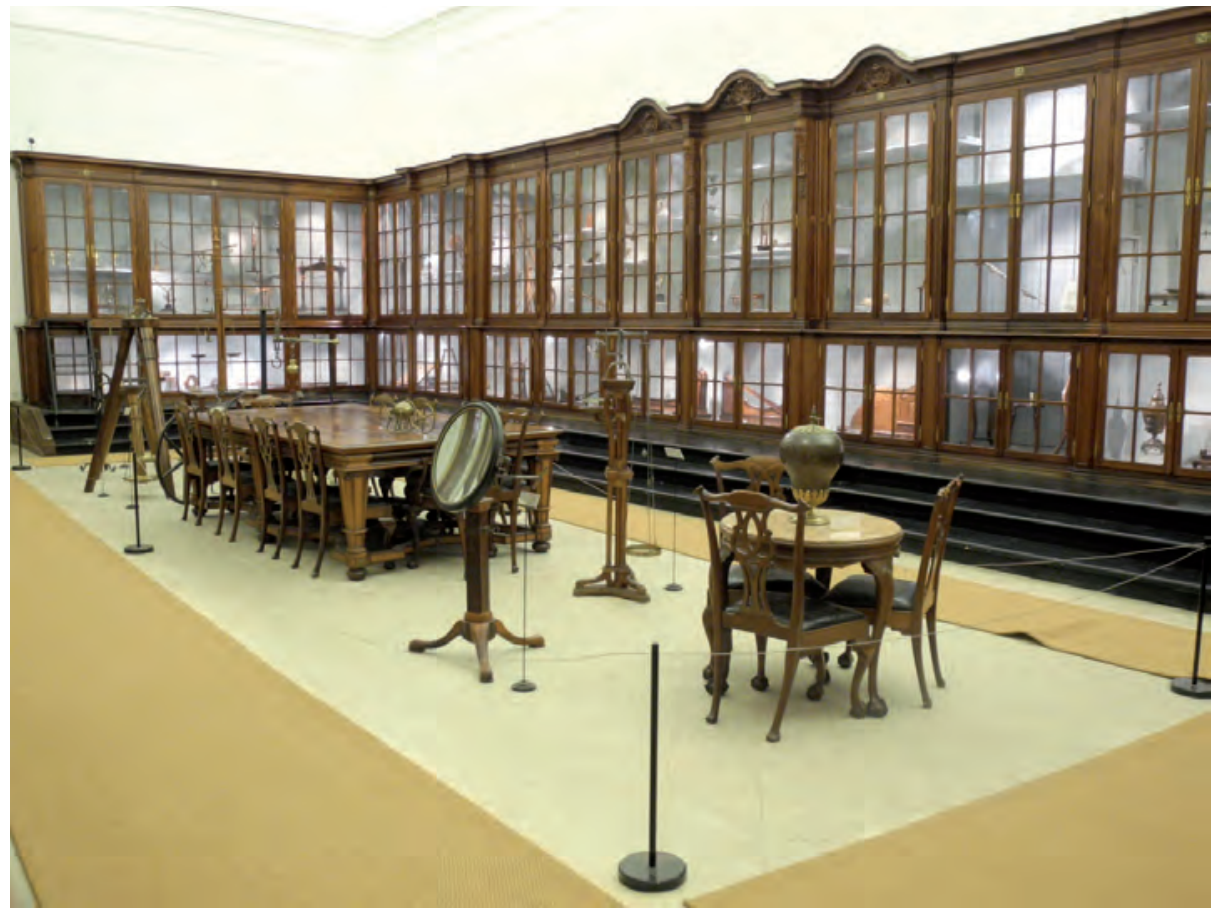

Figura 6 - O Gabinete de Física (fotografia de Gilberto Pereira).

A reforma criou ainda o Jardim Botânico e o Observatório Astronómico. O Jardim Botânico é ainda hoje um dos tesouros da cidade de Coimbra. Já do Observatório Astronómico pombalino nada resta. Foi demolido nos anos 40 do Séc. XX, durante as obras de requalificação da Universidade, por ordem expressa de Salazar, com o polémico objectivo de deitar abaixo aquela excrescência do Observatório Astronómico para deixar intacto aos olhos encantados o panorama maravilhoso do Mondego, das Lágrimas, da quinta das Canas, do Seminário, das encostas de tristes oliveiras... [2].

O projecto do Museu da Ciência compóe-se de duas fases: a primeira consistiu na requalificação e adaptação do Laboratório Chimico à função museológica; a segunda irá requalificar o edifício do antigo Colégio de Jesus.

\section{O Gabinete de Física}

A colecção de instrumentos científicos e didácticos de Física da Universidade de Coimbra é, decerto, uma das mais notáveis e raras da Europa. Estabelecida inicialmente no Colégio dos Nobres em Lisboa por Dalla Bella, foi transferida para Coimbra para fundar o Gabinete de Física associado à disciplina de Física Experimental entretanto criada pelos Estatutos Pombalinos de 1772 (Fig. 7). Dalla Bela, que entretanto tinha regressado a Pádua, foi convidado a voltar a Portugal, desta vez para Coimbra, tendo sido um dos responsáveis pela transferência da colecção de Lisboa para Coimbra. 


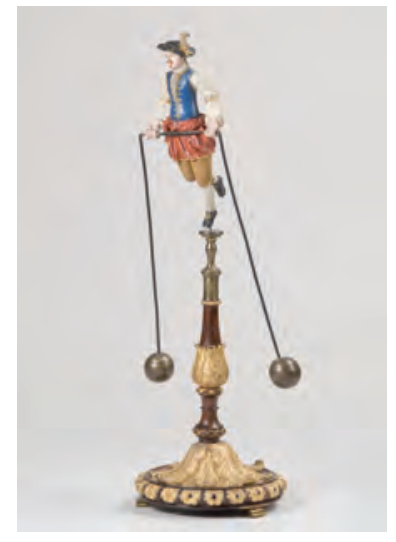

Figura 7 - Um exemplar emblemático transferido do Colégio dos Nobres e ainda em exposição no Gabinete de Física é o equilibrista (FIS.0021), um instrumento de demonstração do centro de gravidade de um corpo, na forma de um equilibrista trajado à época (fotografia de José Meneses).

Ao Gabinete chegaram, ao longo de mais de dois séculos, máquinas, aparelhos e instrumentos que o foram enriquecendo, acompanhando o desenvolvimento da física experimental. O que resta do Gabinete de Física do século XVIII são hoje verdadeiras obras de arte, valorizadas pela riqueza dos materiais e pela perfeição na execução, que ainda ocupam as salas e o mobiliário originais. A colecção conta com mais de três mil objectos de que fazem parte cerca de quinhentos livros antigos.

\section{O Gabinete de História Natural}

De acordo com os Estatutos da Universidade, o Gabinete de História Natural da Universidade de Coimbra deveria englobar não só colecçôes particulares, mas sobretudo colecções resultantes de colheitas efectuadas ou coordenadas pelos professores da Faculdade de Filosofia. Deste modo se deu o progressivo enriquecimento do espólio do Gabinete de História Natural, iniciado com a incorporação das colecções privadas de Domenico Vandelli e de Rollen Van Deck, e fortemente enriquecido com as remessas que ao longo de anos foram enviadas do Brasil por Alexandre Rodrigues Ferreira (1756-1815), recolhidas no âmbito da sua Viagem Philosophica (1783-1792) à Amazónia. No final de 2010, no âmbito de um levantamento das colecções científicas pertencentes à Universidade de Coimbra, foram encontrados 68 exemplares do Séc. XVIII de peixes do Brasil, de diferentes espécies, conservados em seco e montados sobre cartão segundo a técnica de herbário, que fazem parte das recolhas efectuadas por Alexandre Rodrigues Ferreira (Fig. 8).

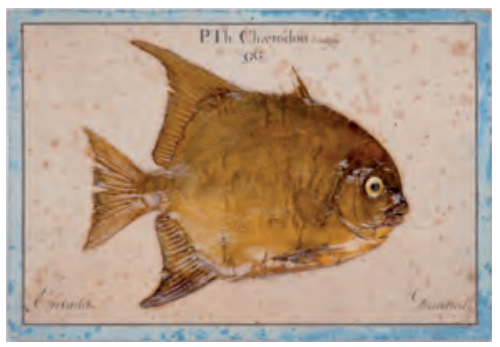

Figura 8 - Um exemplar de peixe conservado com a técnica de herbário, recolhido por Alexandre Rodrigues Ferreira no final do Séc. XVIII (fotografia de José Meneses). 
Em Portugal conhecem-se mais alguns exemplares de peixes conservados com esta técnica, que pertencem à colecção da Academia das Ciências, mas a maioria dos que existiam no país no Séc. XVIII foram transferidos para Paris por ocasião das invasões francesas, fazendo hoje parte do acervo do Museu de História Natural de Paris.

\section{As Colecções}

Para além do Herbário que contém mais de 800000 exemplares, as colecçōes científicas da Universidade de Coimbra compreendem cerca de 240000 objectos distribuídos por quatro categorias principais - História Natural, Etnografia, Instrumentos Científicos, Modelos - e ainda mais de duas mil obras em papel que incluem livro antigo, cartografia, painéis pedagógicos e arquivos. Cerca de $90 \%$ destes objectos são exemplares de História Natural das áreas da Zoologia, Geologia, Botânica e Antropologia. Os instrumentos e objectos de astronomia, física, química, história natural e medicina do século XVIII documentam de forma exemplar o ideal iluminista da busca pelo conhecimento científico (Fig. 9).

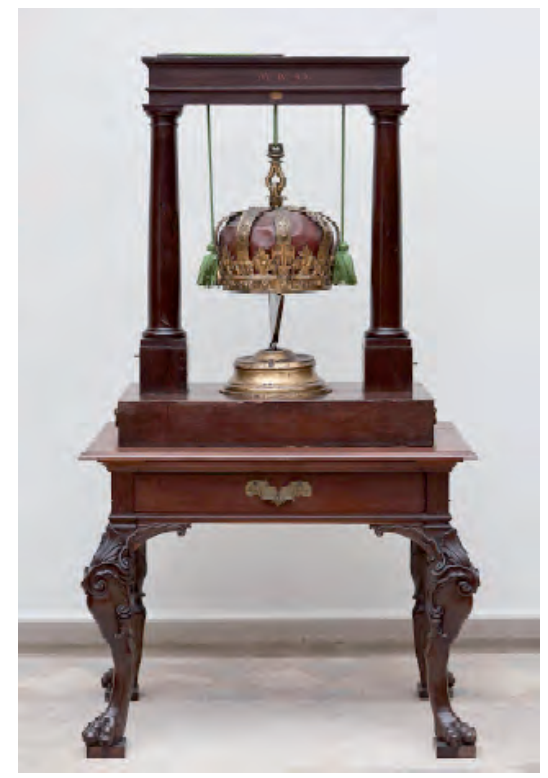

Figura 9 - O magnete chinês é um dos objectos emblemáticos do Gabinete de Física e a sua história antecede o Colégio dos Nobres. O instrumento possui uma magnetite oculta numa armação que representa a coroa real. A magnetite foi um presente do Imperador da China a João V, Rei de Portugal, e o instrumento foi armado por William Dugood (1715-1767), membro da Royal Society que viveu em Portugal (fotografia de José Meneses).

Zoologia - A colecção zoológica é a mais numerosa, atingindo cerca de 200 mil exemplares. Contém o maior exemplar animal em museus portugueses, um esqueleto montado de uma baleia de 20 metros de comprimento, em exposição permanente na Galeria de Zoologia do Museu da Ciência. A colecção de vertebrados representa 5\% do total e é composta por peles de espécimes de mamíferos, aves e peixes conservadas 
em seco e montadas para exposição; espécimes completos de répteis e anfíbios conservados em líquido; e uma colecção osteológica de esqueletos montados e crânios. Entre os mamíferos encontram-se exemplares únicos a nível nacional, nomeadamente um exemplar de urso e um casal de cabras do Gerês, ambos extintos em Portugal. Os invertebrados representam o resto da colecção, dos quais $75 \%$ são insectos. As colecções mais importantes são as de escaravelhos, borboletas e conchas.

BotÂNICA - O espólio de botânica é composto por uma colecção de mais de três mil exemplares de frutos, sementes e ramos conservados em seco ou em líquido e uma série de produtos vegetais como resinas, gomas, fibras, cascas e madeiras do Brasil e países africanos de expressão portuguesa. Existe uma colecção importante de cerca de quinhentos modelos de flores e frutos, em cera e papier-maché, produzidos pelas mais famosas casas de modelos na Europa de finais do séc. XIX: Ziegler, Vasseur, Auzoux e Brandel. O acervo de espécimes vegetais é complementado por uma valiosa colecção de fósseis de plantas, de instrumentos como microscópios e lupas, e ainda uma série de artefactos produzidos com materiais vegetais.

Mineralogia e Geologia - No último quartel do Séc. XIX, o Museu de História Natural foi dividido em secçóes, de acordo com as grandes áreas das Ciências Naturais, sendo então criado o Museu Mineralógico e Geológico, que hoje integra a Galeria de Mineralogia do Museu da Ciência. As colecçóes de mineralogia, geologia e paleontologia estimam-se em mais de vinte mil exemplares com origem nas colecções criadas no fim do séc. XVIII, resultado de recolhas em Portugal e países de expressão portuguesa. A colecção paleontológica, de cerca de dez mil fósseis, é a mais numerosa. $\mathrm{O}$ acervo mineralógico constitui uma colecção de minerais portugueses e estrangeiros com cerca de cinco mil espécimes, assim como um conjunto de modelos cristalográficos (Fig. 10). As colecçôes de rochas de Portugal e estrangeiras contêm mais de seis mil amostras.

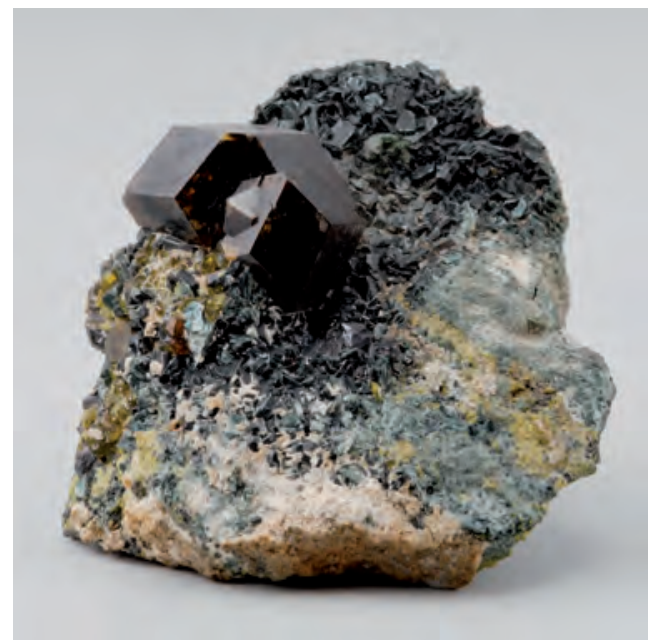

Figura 10 - O mineral Andradite (MIN.SIL.001143), assim nomeado em homenagem a José Bonifácio de Andrada e Silva (fotografia de José Meneses). 
Da colecção de mineralogia faz parte o mineral Andradite, assim nomeado em 1868, em homenagem ao mineralogista José Bonifácio de Andrada e Silva (1763-1838), professor de Metalurgia da Universidade de Coimbra no início do século XIX, que lutou pela liberdade e independência dos povos. Prova da luta que desenvolveu toda a sua vida é o facto de Andrada e Silva ter participado na resistência durante as invasões francesas em Portugal e ter sido em seguida figura central do processo de independência no Brasil.

Antropologia - A colecção antropológica é um acervo de cerca de quatorze mil objectos constituído por colecçóes etnográficas e de osteologia humana, tendo como núcleo inicial a colecção recolhida por Alexandre Rodrigues Ferreira, na sua Viagem Philosophica à Amazónia no séc. XVIII. Durante a sua viagem, descreveu a aparência, vestuário, adereços, armas, tatuagens e costumes das comunidades índias. Apenas a título de exemplo, Alexandre Rodrigues Ferreira recolheu junto dos índios Jurupixuna várias máscaras usadas em danças de agradecimento ou celebração que remeteu para o Real Museu da Ajuda e que foram integradas na Universidade de Coimbra em 1806, em conjunto com todo o material recolhido durante a viagem. A tribo Jurupixuna já não existe, nem deixou quaisquer máscaras como estas no Brasil, sendo hoje o conjunto de máscaras raríssimo e de valor incalculável (Fig. 11).

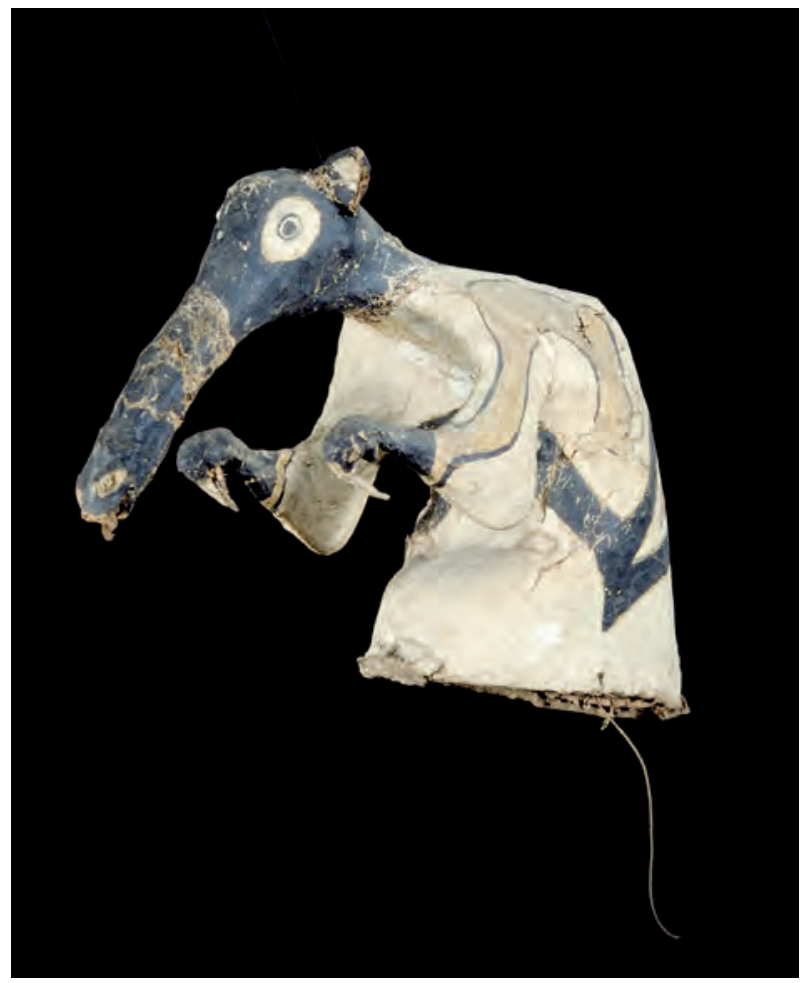

Figura 11 - Máscara zoomorfa usada pelos índios Jurupixuna, que representa um papa-formigas (ANT.Br.137).

Foi recolhida por Alexandre Rodrigues Ferreira durante a sua Viagem Philosophica ao Brasil, no Séc. XVIII (fotografia de Carlos Barata). 
As colecções etnográficas, recolhidas na sua maioria durante o séc. XIX, representam Portugal e os países de língua portuguesa: Brasil, Angola, Moçambique, S. Tomé, Guiné, Macau, Timor e Goa entre outros. Do acervo faz também parte uma colecção notável de modelos de frenologia.

Química - A colecção de química tem o seu início associado às actividades de ensino e de investigação implementados no Laboratorio Chimico em 1772. Destaca-se pela sua raridade uma colecção de fornos cerâmicos de reverbero fabricados no próprio laboratório, assim como um conjunto de sete potes de botica em faiança do fim do séc. XVIII, da fábrica de Domenico Vandelli. A colecção no seu conjunto reúne, para além das raridades da química do séc. XVIII, mais de mil peças maioritariamente datadas do séc. XIX e XX. Deste núcleo faz parte um conjunto de mobiliário químico de bancadas e nichos de evaporação, e um grande número de balanças, retortas, frascos e estufas.

Astronomia - O núcleo mais antigo da colecção de astronomia está associado à actividade científica do Observatório Astronómico fundado no Séc. XVIII, que incidia no estudo da astronomia e da matemática para a geografia e para a navegação. O Padre Monteiro da Rocha, matemático e astrónomo, foi nomeado director do Observatório Astronómico em 1795, equipando-o com instrumentos vindos do Colégio dos Nobres de Lisboa e com encomendas ao construtor João Jacinto Magalhães em Londres. Fazem parte da colecção alguns instrumentos da autoria de um dos mais importantes construtores de instrumentos científicos do Séc. XVIII, George Adams (Fig. 12).

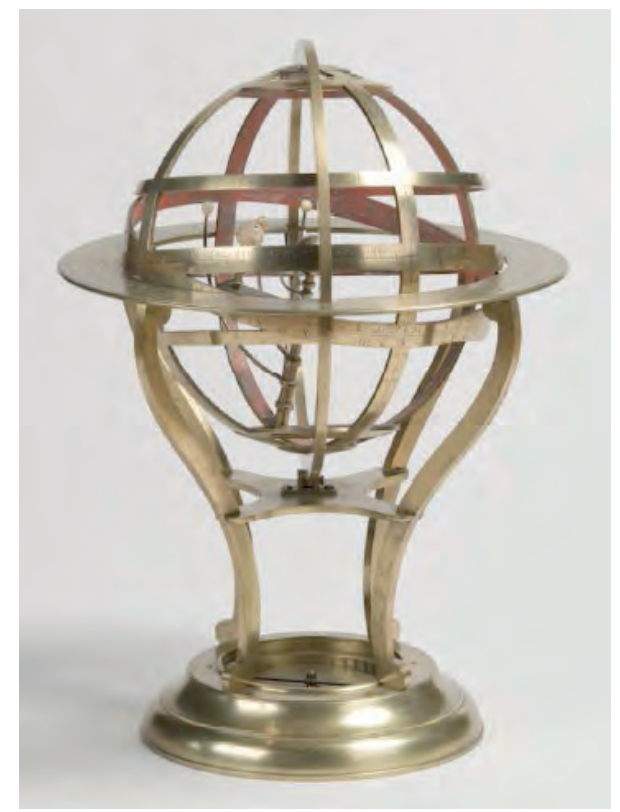

Figura 12 - Esfera armilar com planetário (AST.I.006), construída por George Adams, séc. XVIII. Trata-se de um modelo da Terra, do Universo e do Sistema Solar. A esfera possui, no seu interior, um planetário com o Sol no centro rodeado pelos planetas conhecidos na época (fotografia de José Meneses). 
A colecção de astronomia foi saqueada pelas tropas napoleónicas durante as invasões francesas em Coimbra, em 1810. Da colecção faz hoje parte, ironicamente, uma pêndula de compensação de Berthoud, um instrumento utilizado para a determinação da hora de observaçôes astronómicas, que caiu durante o saque partindo-se uma roda dentada, tendo o oficial encarregado desistido dele. A colecção actual é constituída por cerca de mil objectos que incluem mais de 200 instrumentos de observação, complementados por um conjunto de acessórios e ferramentas. Existe ainda uma colecção de desenhos, mapas e cartas celestes assim como um núcleo de livro antigo.

\section{CONCLUSÃo}

Ao longo de mais de dois séculos, foram muitos os que contribuíram para a colecção de Coimbra, adquirindo, produzindo ou sugerindo a inclusão de novos objectos. Falámos do Marquês de Pombal, de Vandelli, de Monteiro da Rocha, de Alexandre Rodrigues Ferreira, assim como de outros homens dos Séc. XVIII e XIX, fundamentais para a construção e preservação deste verdadeiro tesouro científico e patrimonial. Mas foi preciso que um convidado estrangeiro, Robert Bud, do Museu de Ciência de Londres, já no Séc. XXI, visitasse os Gabinetes Pombalinos de Coimbra e exclamasse: "sinto que foi aqui que nasceu o Iluminismo!", para que todos compreendessemos que o Museu da Ciência da Universidade de Coimbra já tinha nascido no Séc. XVIII, na sequência de uma transformação radical das mentalidades em toda a Europa, abaladas que estavam pelo terrível terramoto de Lisboa, já preparadas para ouvir as palavras revolucionárias de Voltaire, transformação essa que viria a culminar com a revolução francesa poucos anos depois.

Coimbra foi atacada e espoliada no início do Séc. XIX, mas mesmo assim, a colecção continuou vasta e valiosa. O Séc. XX iria destruir o Observatório Astronómico e o Gabinete de Física Experimental esteve prestes a ser barbaramente diminuído, não fosse a intervenção providencial de Mário Silva (1901-1977). Apesar de todos os contratempos, uma boa parte da colecção do Século das Luzes conseguiu chegar intacta ao Séc. XXI. Actualmente estão a ser dados passos muito importantes para que nos possamos orgulhar do passado e do património acumulado. O Museu da Ciência é um projecto de grande fôlego da Universidade de Coimbra, que visa a preservação, a divulgação e o estudo deste valioso património do iluminismo nacional, que tem vindo a desenvolver todo um programa de acçôes para esse objectivo, com grande impacto nacional.

\section{BiBLIOGRAFIA}

[1] ESTATUTOS da Universidade de Coimbra, Coimbra, 1772.

[2] SALAZAR, António de Oliveira. Discursos e Notas Politicas, II: 1935-1937. Coimbra Editora, Coimbra, 1937.

[3] MUSEU da Ciência Luz e Matéria (coord: Paulo Gama Mota). Catálogo de exposição. Universidade de Coimbra, Coimbra, 2006.

[4] LABORATÓRIO do Mundo: Idéias e Saberes do século XVIII (pesquisa e textos: Artur Soares Alves et al.). Catálogo de exposição. Pinacoteca do Estado de São Paulo, São Paulo, 2004. 
[5] CAllapeZ, Pedro M.; MARQUES, Júlio F.; PAREDES, Ricardo; ROCHA, Carla. 'Retrospectiva histórica das colecções de paleontologia do museu mineralógico e geológico da Universidade de Coimbra', pp 61-68, in Colecções e Museus de Geologia: Missão e Gestão, (eds: José M. Brandão, Pedro M. Callapez, Octavio Mateus e Paulo Castro), Fundação para a Ciência e a Tecnologia, Ministério da Ciência e do Ensino Superior, Coimbra, 2010.

[6] PIRES, Catarina Pereira. Laboratório Chimico da Universidade de Coimbra: interpretação histórica de um espaço de ensino e divulgação da ciência (Dissertação de Mestrado), Universidade de Aveiro, 2006. 